\title{
Aligning pedagogy and technology: A case study using clickers in a first-year university education course
}

Sue Monk, The University of Queensland, s.monk@uq.edu.au

Chris Campbell, The University of Queensland, chris.campbell@uq.edu.au Simone Smala, The University of Queensland, s.smala@uq.edu.au

\begin{abstract}
This paper presents the results of a case study which focuses on lecturers' use of a learner response system (clickers) with students enrolled in a first-year university education course. Data is drawn from interviews and questionnaires with guest lecturers, including the course coordinator and co-author of the paper, who is also the principal lecturer in the course.

Within the body of research that links clicker use with positive student engagement, this paper focuses on the lecturers' experiences in preparing for, and using clickers with their students. The study focused on the research question: How do pedagogical decisions affect the way clickers are used with students in an education course? Taking into account the located-ness of individual lecturers' pedagogical frameworks, the results of this study indicate a connection between lecturers' teaching pedagogies, the way these inform their interactions with students and also how they incorporate clickers in their teaching. This paper therefore argues that the objectives of using clickers need to be made explicit in pedagogical dialogues of teaching teams comprised of lecturers and guest lecturers, and clearly linked to the overall pedagogy informing a course delivery.
\end{abstract}

Keywords: learner response system, clickers, pedagogy reform

\section{Introduction}

Tertiary pedagogy reform has been a central concern for many universities since the dawn of the digital age. Laurillard (2002) maintains that "for some time now, academics have been arguing for a radical shift from the standard transmission model of university teaching” (p. 18). 'Learning communities', when mediated through digital tools, need to provide engagement for students at different levels. Students need to engage with curriculum content to develop their own competence, they need to have personal experiences of engagement with others, and their developing competence needs to be incorporated within learning community participation (Wenger, 1998, cited in Laurillard, 2002, p. 20).

In this article, we investigate the use of clickers as a means of supporting pedagogical reforms in the social sciences, specifically in education. Research into the effectiveness of engaging students through the use of learner response systems, specifically clickers, has been prolific in the science and mathematics disciplines (Gray \& Steer, 2012; Patterson, Kilpatrick, \& Woebkenberg, 2010; Sevian \& Robinson, 2011; Wit, 2003). Further investigation into specific benefits of clicker use and enhanced student learning has also emerged in the behavioural sciences, such as psychology (Anderson, Healy, Kole, \& Bourne, 2011). This paper seeks to complement that research by presenting data drawing on the social sciences, in particular education, where clicker use has not seen the same level of uptake.

Given the statement by Anderson et al. (2011, p.1457), that "there is no standard method for using the clicker system most effectively, thus leaving instructors to their own discretion", this case study seeks to investigate how lecturers in the field of education interpret the pedagogical benefits of using clickers with their students. Moreover, as Broussard (2012) points out, there is a need to balance the focus on student outcomes with an understanding of the effects of clicker use on the lecturers themselves, as potential partners in learning.

\section{Background to the study}

This paper presents the results of a case study which focused on lecturers' use of clickers with students enrolled in a first-year university education course. The study investigated lecturers' attitudes to using clickers and the perceived pedagogical benefits, opportunities and obstacles associated with their use in a large undergraduate course. The impetus for this study came from an earlier trial phase where the course coordinator/lecturer used clickers with students in one tutorial group as a way of exploring possibilities for increased participation in the course. Initial findings demonstrated increased engagement and understanding of course content throughout the semester, improved interaction between students and the lecturer and enhanced student feedback (Campbell \& Monk, 2012). During the trial it was noted that the lecturer also began to focus more specifically on the types of responses that could be elicited from students via the clickers and how these matched her usual approach to preparing questions as part of the course delivery.

Following this trial it was decided to expand the research to include guest lecturers in the course, and investigate if, and how, they changed their approach to eliciting student responses when invited to use clickers with the full student cohort. In particular, the study shifted its focus to the pedagogical considerations that guided their decisions when designing questions for use with clickers in class.

\section{Literature Review}

University teaching is often characterised by large classes with potentially hundreds of students sitting opposite one lecturer. This situation has given rise to research focussing on how to engage large numbers of students interactively. Charman and Fullerton (1995, quoted in Ramsden, 2003, p.174) found that students in large lectures benefitted from being able to discuss in groups crucial concepts or topics that had been first introduced verbally by the lecturer and supported by written notes handed out at the beginning of the lecture. Questions that arose during this discussion were either discussed later in the lecture or put into a question box to be addressed by the lecturer in the next lecture. This interactive and student- centred approach, explicitly encouraging student voices, informs the pedagogical decisions for using clickers. 
Student-centred learning, as a pedagogical approach, sits comfortably within the social constructivist orientation that informs contemporary teaching and learning practices in education (McLoughlin \& Lee, 2008). This means that there is an emphasis on "the social context for learning... [and] that students are the key initiators and architects of their own learning and knowledge-making, rather than passive 'vessels' who receive the transmission of knowledge from 'expert' teachers” (Barraket, 2005, p. 65). Tutorials and small group teaching is conducive to this pedagogical approach, where opportunities for peer-to-peer learning and "substantive conversation" (Lingard, Hayes \& Mills, 2003) can occur between the lecturer and students. However, research shows that enabling student-centred learning with large student cohorts in lectures remains challenging (Kerr, 2011; Murray \& Poyatos- Matas, 2004; Oliver, 2007). Concern with developing effective pedagogical strategies in large undergraduate courses is a situation likely to continue due to continuing economic pressures which favour courses with large student enrolments (Oliver, 2007) thus reinforcing the likelihood that it is in these contexts where new practices for monitoring student engaging and learning will be tested.

\section{Learner response systems}

Learner response systems, such as clickers, have been used to address this concern over student engagement in large courses and there is now a large body of research that has been conducted on their implementation (Beatty \& Gerace, 2009; Hall, Collier, Thomas, \& Hilgers, 2005; Milner-Bolotin, Antimirova, \& Petrov, 2010) with others reporting specifically on implementation models (Barnett, 2006; Koenig, 2010; White, Delaney, Syncox, Akerberg, \& Alters, 2011). Early research suggests that one of the positive findings of using clickers when teaching is that students like receiving feedback about how well they understand the material they are learning (Barnett, 2006). Another positive finding is that clickers can be used in both lectures and tutorials and they can be used with various question types (Caldwell, 2007).

The use of clickers "may act as a powerful catalyst to transform them, moving them from teacher-centred conceptions and approaches to teaching to student-centred conceptions and approaches" (Kolikant, Drane, \& Calkins, 2010, p. 134). Thus, there is evidence to suggest that using clickers can promote student-centred learning and facilitate a constructivist learning environment which also provides timely student feedback (Barnett, 2006; Beatty \& Gerace, 2009). However, McGloughlin and Lee (2008, p.642) caution that "not all student centred learning activities are constructivist in nature", implying a need to probe further into the varied, contextualised ways that lecturers use this technology to support their pedagogical approach.

Whilst it is widely reported that a pedagogical framework to scaffold learning is important when using clickers in teaching (Beatty \& Gerace, 2009; Hoekstra \& Mollborn, 2011; Milner-Bolotin et al., 2010), the central role of questioning is a specific part of the teaching and learning process that points to how pedagogical decisions about student-centeredness are made. The questions we ask students are important because: [Q]uestioning is central to eliciting explanations, postulating theories, evaluating evidence, justifying reasoning and clarifying doubts. Thus, our central premise is that the act of questioning can lead learners to engage in critical thinking and reasoning. (Pedrosa de Jesus, da Silva Lopes, Moreira, \& Watts 2012, p. 560)

\section{Questioning using clickers}

Several studies highlight the effectiveness of different question-types in the learning process and the need to stimulate independent and critical thinking amongst students by posing a range of carefully-constructed, usually open-ended questions (Atkinson \& Hunt, 2008; Ertmer, Sadaf, \& Ertmer, 2011; Farmer, 2007). Whilst Caldwell (2007) provides an overview of question-types that are commonly used with clickers, Keller, Finkelstein, Perkins, Pollock, Turpen, \& Dubson (2007) found that the most effective way of using clickers was to "ask conceptual questions appropriate for most students' level of knowledge" and "encourage students to discuss with their peers during clicker questions and create environments that get students to discuss” (p. 131). Abrandt-Dahlgren \& Öberg (2001), on the other hand, identified a range of question types useful for problem-based learning. These include encyclopaedic, meaning-oriented, relational, value-oriented and solution-oriented, according to the changing focus and stages of the learning tasks. The message that has been most strongly reinforced in our review of the literature is that questions are central to "[r]ecovering students' voices [which] helps bring them into the fold as co-learners and co-teachers” (Fobes \& Kaufman, 2008, p. 27). It is this combination of questioning with clicker use, and how it connects to lecturers' pedagogical approaches to student centeredness, which is the focus of our paper. We turn now to the methodology for our case study before presenting our findings.

\section{Methodology}

This case study centred on a first-year university education course which included 180 undergraduate students, the course coordinator and principal lecturer (referred to as Lecturer

1) and six guest lecturers (referred to as Lecturer 2, Lecturer 3, etc.). The course, Introduction to Education, runs for 13 weeks each year and comprises a two-hour lecture and a one-hour tutorial. This is a mandatory course for students enrolled in a Bachelor of Education course or for those wishing to complete course requirements towards a teaching degree. As an introductory subject it covers a broad range of topics with one of the aims of the course to "stimulate students' thinking about key educational questions of why, what and how we educate with a particular focus on social justice” (http://www.uq.edu.au/study/course.html?course_code=EDUC1029).

The course also regularly includes guest academics and lecturers. Due to the nature of the content, sociology of education, general questions and topic introductions by lecturers in a whole lecture situation are often framed to elicit students' ideas and opinions in order to gauge what they already know about education in the Australian context and what beliefs they hold, particularly given that many controversial educational issues are regularly presented in local and national media. There is a social justice orientation to the course and issues such as current debates about school funding models, and inequity in educational outcomes, are often presented for analysis and discussion. Pedagogical frameworks such as critical pedagogy and action research have helped shape the design of the course and the learning activities across several iterations of the course delivery. For this reason it is considered imperative that effective methods are used for engaging students in substantial dialogue and productive conversations, what could also be termed "substantive conversation" (Lingard, Hayes \& Mills, 2003) referred to earlier in this paper, that will help deepen their analysis of the current educational environment. 
Approval for the study was granted by the university's ethics committee before the commencement of the course. Each of the six lecturers who were scheduled to give a guest lecture in the course was then invited to participate in the study along with the principal lecturer (Lecturer 1). First, the researchers met with each guest lecturer individually to explain the objectives of the project, provide information and consent forms to participate in the study, and to answer any initial questions they might have in relation to IT support for preparation and clicker use during their lecture. During this initial meeting the guest lecturers were also asked to think about 1) whether they usually asked questions of students during their lectures, and 2) the types of questions they usually asked (for example, high or low- order questions, questions to demonstrate their understanding of subject content or concepts, or stimulus questions to elicit a range of opinions). The ICT support person in the study then demonstrated the clicker technology and explained the range of question types that could be used, such as yes/no, true/false, Likert scale, multiple choice and open-ended questions. This initial meeting finished with a request that each of the guest lecturers prepares two or three questions for students that they would like to use in their lecture. These questions were to be sent to the ICT support person to be uploaded to their PowerPoint slides before their lecture.

Finally, they were asked to complete an online questionnaire before their lecture about previous experiences using clickers or how they might think about the preparation of future questions for the students.

Questions for the pre-lecture online questionnaire were as follows:

1) Have you used clickers before?

2) If you answered 'yes', please tell us about your experiences with this technology.

3) Have you used ActivEngage before (the type of clicker that Education has purchased)?

4) If you answered 'yes', please tell us about your experiences with ActivEngage.

5) When you are preparing your lecture, do you usually prepare questions you are going to ask students?

6) When you present lectures, what type of responses do you like to elicit from students?

7) Knowing that you are going to be using clickers/Active Engage in your guest lecture, are you preparing different questions?

8) If you answered 'yes', how are you changing what you usually do? (You can select multiple answers).

a. Different wording

b. Different formats - yes/no, multiple choice, open ended, Likert scale

c. Eliciting different types of responses (lecture content, thinking process, etc)

d. Other

9) After reading the information sheet (for the study), how do you expect your experiences will be different using the clickers/Active Engage? If so, how?

10) How do you think that using the clickers in class will change how you present your lecture information?

11) Would you like feedback about the use of clickers? You are welcome to make comments either through the survey link or via Facebook or Blackboard.

Following completion of the pre-lecture online questionnaire, the guest lecturers prepared their questions and sent them to the ICT support person who uploaded them to slides in PowerPoint ready for their lecture. Following their lecture, each guest lecturer was asked to complete a post-lecture online questionnaire. This included the following questions:

1) Was this the first time you had used clickers or ActivEngage?

2) Tell us about your experiences using this technology in the EDUC1029 lecture.

3) When you are preparing your lecture, do you usually prepare questions you are going to ask students?

4) When you present lectures, what type of responses do you like to elicit from students?

5) Knowing that you were going to be using clickers/Active Engage in your guest lecture, did you prepare different questions?

6) If you answered 'yes', how did you change what you usually do? i.e. What did you do differently to prepare your lecture?

a. Different wording

b. Different formats - yes/no, multiple choice, open ended, Likert scale

c. Eliciting different types of responses (lecture content, thinking process, etc)

7) After using clickers/ActivEngage, were your experiences different from what you were expecting? If so, how?

8) Are there any other comments you would like to make about your experience of using clickers in the lecture?

9) Would you like feedback about the use of clickers? You are welcome to make comments either through the survey link or via Facebook or Blackboard.

Triangulation of data collection was achieved through the use of these two online questionnaires (pre and post-lecture), analysis of the clicker 'question' slides which were used during the lectures, and post-lecture interviews where we invited guest lecturers to participate in a semi-structured interview to reflect on the way their pedagogical decisions influenced the types of questions they used. The interview began with the following stimulus questions:

1) How did you feel the questions/clickers worked with your lecture?

2) How did using clickers influence the way you asked questions?

3) What is your usual approach to lecturing? What kind of pedagogical considerations affected how you felt, what you did, how you have reflected on your experience using them in your lecture? 'What benefits did you perceive in using the clicker technology?' etc. 
Interviews play an important role as a strategy in the methodology for this case study. As is common to social science research, case studies can reveal phenomena in action, not isolated from context and influences. All guest lecturers completed the online questionnaires however only three were available for the final interview. Whilst general conclusions cannot be drawn from this small case study, the lecturers' own accounts of their experiences can provide “directly transferable insights” (Lyons, 2009, p. 32).

Moreover, contextualised data obtained from case studies can reveal the complexity of pedagogy in practice and "invite readers into acts of experiential comparison” (Bullough, 2012, p. 352). The following Results and Discussion section begins with the course coordinator/principal lecturer's (Lecturer 1) account of the pedagogical decisions that informed her use of clickers in relation to the objectives of the course. Unlike the guest lecturers who were mostly unfamiliar with using clickers and only had the one occasion to use them in the course, the principal lecturer used clickers regularly throughout the course. As additional data this research draws on examples from the reflective notes and observations of guest lecturers' use of clickers kept throughout the course.

\section{Results and Discussion}

\section{Responses to clicker use by the course coordinator/principal lecturer (Lecturer 1)}

Lecturer 1 was involved in the research project in the following ways. These include:

1) Two aspects of the clicker use which were her own development of clicker questions and the use of clickers during lectures;

2) Information sessions with guest lecturers to discuss the use of clickers and the types of questions considered for clicker use; and,

3) Lecture observations of guest lecturers' use of clickers. The following section includes the principal lecturer's own observations and reflections on these three aspects, as well as a discussion of how they relate to the pedagogical decisions she made in preparing for clicker use with her students.

The development of clicker questions and the use of clickers during lectures

The focus of the course Introduction to Education is the presentation and engagement with social justice concepts in education. As such, the course addresses different schooling outcomes for different groups of Australians, and provides conceptual frameworks to explain these differences. For many students, this approach seems to come as a surprise, and the conceptual engagement with concepts like 'cultural capital' or 'whiteness' is not what they expected. The objective when considering clicker questions was therefore first and foremost a design that would enable engagement with ideas that were new to many students.

Having established her objectives, the lecturer tried to devise questions that would provide as much information as possible to treat this phase of the lecture as an opportunity to focus the students' attention on thinking about new concepts. In particular, the most successful clicker session identified was after the first few lectures and before the submission date of the first written assignment. It was decided to use a multiple choice structure where students voted for one correct answer, and this approach included answers to choose from that gave extensive information. In addition it was decided to use a structure that would provide a choice of one correct answer and two or three other answers. The questions themselves were, as a consequence, very simplistic, for example "What is 'cultural capital'? The information that was given in the two 'wrong' answers was elicited from assignments in previous semesters. These two 'wrong' answers were generally speaking representing misunderstandings about concepts that students often seem to have in the beginning of the course. ('Wrong' must be read here in inverted commas, as the conceptual errors students made in their assignments can simply be understood as steps towards a deeper understanding of concepts such as 'cultural capital', 'essentialism', or 'social reproduction').

While the correct answer was shown and explained after each clicker voting, the two other answers were problematized and discussed as well. The students therefore had two opportunities to think about concepts, first when they were reading the possible answers to the clicker questions, and then when the answers were discussed. Having to vote for an answer made students read the answers with more concentration, including weighing up which of the sometimes quite similar answers best represented the concept.

One of the problems encountered in this process was the wording of the answers. While Lecturer 1 found it relatively easy to formulate an answer that she felt best represented the concept, it was much more difficult to formulate 'wrong' answers which were often based on ideas that actually feed into the concept, but were too limited in scope. This was one of the major differences from less 'ideas'- based university disciplines, such as science and engineering. The humanities students in this lecture could not simply be given specific information in note form and through verbal instruction, like in the above-mentioned Charman \& Fullerton (1995) study. The aim in sociology of education is more on offering a new perspective on familiar observations, for example the differences in schooling achievements for different groups in society.

The 'wrong' answers often turned out to be simply sub-aspects of the concepts, and when students were asked to vote for the "one correct answer" they were actually receiving a message that those sub-aspects in the 'wrong' answers were not part of the concept. This experience supports the findings presented above that the effectiveness of different question- types in the learning process and the need to stimulate independent and critical thinking amongst students by posing a range of carefully-constructed, usually openended questions (Atkinson \& Hunt, 2008; Ertmer, Sadaf, \& Ertmer, 2011; Farmer, 2007) is paramount in a student-centred pedagogical approach. Due to the lecturer's view that the answers to the questions were restricting students' independent and critical thinking, when this multiple choice structure was used again in a later lecture, the wording was changed. Students were subsequently asked to vote for the answer that 'best and most comprehensively' represented the concept. This gave the lecturer an opportunity to point out how aspects in the other answers might also be present in the concepts, but were not giving the complete picture. 


\section{Information sessions with guest lecturers to discuss the use of clickers and the types of questions considered for clicker use}

Information sessions with the other guest lecturers provided an opportunity to reflect on the clicker use in general, and to summarise the kinds of questions and uses encountered so far with this new medium. This was a progressive development, as the later guest lecturers benefitted from information sessions that included reflections on what the guest lecturers before them had tried. In particular, one guest lecturer had developed the idea to use the clickers at the beginning, and then again at the end of the lecture with the same questions and answers, to have an ad hoc testing tool for changed attitudes or increased comprehension. This idea was presented to another guest lecturer, who took it up and used the clickers in the same way.

\section{In-lecture observations of guest lecturers’ use of clickers}

Interestingly, in both cases guest lecturers expected certain changes in the student answers that did not eventuate in the predicted way. This was one of the observations made during guest lectures, and one of the limitations of using the clickers in the beginning and at the end was that the changed answer patterns, expected or unexpected, could not be problematized because of time constraints. This was exacerbated by not having discussed, during the information sessions, ways to preserve the results of the vote in the beginning of the lecture to have them ready for comparison in the end. Results were, therefore, only quickly jotted down by a hastily chosen student, and the potential for problematisation and comparison remained largely unexplored. This particular use of clickers has therefore proven to be only of limited use for an interactive approach to student learning. The main reason was a lack of a 'learning community' in which new concepts and perspectives could be discussed with peer groups. The students were mainly asked to voice their opinion at the beginning and at the end, with the teacher-centred information transmission their only and limited opportunity to devise new methods of reasoning for themselves.

The following section presents extracts taken from questionnaires and interviews with the six guest lecturers. As "experiential comparisons” (Bullough, 2012) similarities and differences in pedagogical approaches begin to emerge.

\section{Responses to clicker use by the participating guest presenters}

Of the six guest lecturers, only Lecturers 2 and 3 had previously used clickers, so for most of the guest lecturers there was initial apprehension about how the process would go and specifically whether the technology would work smoothly and without technological problems. One guest lecturer commented: “I have to say I wasn’t particularly receptive to the idea of clickers. When I'd seen them used in a previous lecture...the technology was a bit bumpy...in terms of it working at the time” (Lecturer 5).

With only a single lecture therefore, there was little opportunity for guest lecturers to develop the degree of confidence, or opportunity for 'fine-tuning' questions that was available to the lead lecturer. However, for Lecturers 2 and 3, who had previous experience using clickers and who jointly presented their lecture, they were accustomed to presenting single lectures (rather than teaching in semesterlong courses) and predominantly taught across several subject disciplines. For them, clickers were used as a tool for summarizing and reinforcing the main points of the lecture, mainly by using Yes/No type questions. In their role as library advisors who were visiting the class for a single presentation, clickers allowed them to keep students engaged. While this approach was not necessarily studentcentred, it allowed the library guest lecturers to deliver lots of information. An example of a clicker question posed by Lecturers 2 and 3 demonstrates this point.

Question: Summon searches often have thousands of results. How can you limit them?

- By year

- By subject

- By type of resource e.g. journal article, book

- By whether the resource is scholarly

- All of the above

This multiple-choice type question is used regularly by these two lecturers who often deliver single lectures to new groups of students at the beginning of their courses. This type of question allows for all students to respond and monitor their own understanding quickly in, what might be otherwise considered, a situation where there is little opportunity for discussion between students and lecturer: "I would say the clicker approach works quite well with an undergraduate cohort, a large one, in terms of keeping them engaged and awake enough to pay enough attention, awake through your presentation” (Lecturer 2).

This comment also draws attention to underlying concerns often related to the common two hour lecture (and one hour tutorial) model that is prevalent with many large undergraduate courses. The implication here is that this format is less conducive to engaging students and that clickers may be seen as an 'activity' to help keep students on-task. In support of this idea, quick quizzes and memory exercises were identified by these presenters as being popular with clicker use. However, they also used multiple-choice questions as a way of helping students test their knowledge and gain feedback about what they remember of the information presented. As library sessions are often information-driven, the pedagogical framework here remained quite teacher-centred, and included the clickers predominantly in a test-type fashion. In other situations, the library guest lecturers had used clickers to allow students to choose from a list of topics those areas that they felt needed more explanation.

Here, the timely student feedback (Barnett, 2006; Beatty \& Gerace, 2009) works in a reverse way, with clicker use providing timely feedback to the guest lecturers:

I used them...for [the students] to control the direction of the lesson so, we had a list in the beginning and they voted 'yes' or 'no', 'we want these components in the class' and then they could do that anonymously with the clickers so they didn't feel like they were embarrassing themselves by saying 'I don't know anything in our database' and so then they designed the class they were happy with....and they were a lot more positive about that particular class because they felt they got more from it. (Lecturer 2)

Meaningful student interaction that gives students voice and agency in controlling information delivery, emerges here as one of the pedagogical strategies that continuously had the best results in our clicker pedagogy experience. For lecturers 4-7, their objectives were different. As was the case with Lecturer 1, these lecturers within the education discipline sought to elicit discussion amongst students, rather than yes/no answers, and summarising main points was considered secondary to developing an understanding of 
different perspectives within a complex scenario that was presented. Due to the lack of previous experience using clickers, these four guest lecturers had requested suggestions and examples of questions types before they began preparing their presentation. During initial discussion, all four guest lecturers believed that open-ended questions would be unsuitable in a lecture with a large student cohort and therefore decided to opt for closed questions. However, this generally did not align with their usual approach to questioning. As Lecturer 4 stated: "[It] will be a bit strange presenting on a teaching strategy that stresses the importance of substantive conversations and then having closed questions”.

In the case of this guest lecturer, despite large student numbers, he was used to being able to interact with students through a series of open-ended questions where he could ascertain levels of interest and understanding without the apparent formality of 'set' questions on a PowerPoint slide. An example of this is the following question: "How do we address the issue of high quality-low equity?" This open-ended question was used as a way of 'framing' a series of issues around equity and access to educational opportunities. Posed as a dilemma, the question set the scene for students to be involved in discussion and debate, for which the lecturer allowed segments throughout his lecture.

Lecturer 4's pedagogical approach to teaching education courses to student teachers was informed by the before-mentioned “[r]ecovering students' voices [which] helps bring them into the fold as co-learners and co-teachers” (Fobes \& Kaufman, 2008, p. 27). Two of the guest lecturers similarly expressed a concern that having set clicker questions was counter- intuitive to their objective of being 'in the moment' with their students or creating questions spontaneously in response to their reading of student receptiveness. Importantly, with guest lecturers who did not know the students:

if it's a guest lecturer, it's very much organically generated and it depends if they're receptive and talking 'cause it can be really hard if you haven’t taken them for the semester and then you suddenly come in and give a lecture and you don't know who they are... and it's not as quick as the repartee of conversation. (Lecturer 5)

Two of the guest lecturers (Lecturers 4 and 5) used graphs to display the responses elicited from their students. Lecturer 4, having had the opportunity to learn of the Lecturer 5's experience with this clicker format, was able to conceptualise a new way of representing student responses. The graphs were used to show how students' responses had changed from the beginning of the lecture to the end. This was a satisfying experience for both the students and the guest lecturers however, this single experience with the clickers was insufficient to enable significant interaction and discussion within the class. In one case the guest presenter needed to have both beginning and end graphs to be displayed beside each other to enable a more nuanced discussion, however time constraints and insufficient familiarity with the technology meant that the guest lecturer was not completely satisfied with the final outcome.

Without the comparative graph [which] is actually quite hard to have, so ...coming back to your ultimate questions, was it productive for them? I think it was, but it had to be tweaked to try and make it more productive so I felt quite constrained by the technology. (Lecturer 5)

Open-ended questions proved to be the most challenging in terms of adapting preferred question-types for use with clickers. In the trial phase which preceded this case study, open- ended questions were used effectively in a small tutorial group of less than 20 students and the diversity of student responses could be saved to their course Blackboard site, providing a useful resource for students to access when writing assignments (Campbell \& Monk, 2012). By contrast, the guest lecturers felt that the large number of responses that could be elicited through open-ended questions would be too unwieldy to read through and respond to in large lectures.

So that steers you towards very different sorts of questions and engaging with their prior learning in a different sort of a way so, it definitely steered me towards asking questions in very concrete aspects of the presentation that I was doing ... it really had a huge impact on how I was approaching the sorts of questions and in the end, I did end up asking one of the open questions because I couldn't ultimately limit myself to yes, no, right, wrong multiple choice questions. They're useful and they serve a purpose but, that was also limiting... (Lecturer 6)

An example of this lecturer's "very concrete” way of bringing students to the lecture content was through a multiple-choice question.

Where do you think the majority of the Indigenous students are attending schools?
a. New South Wales
b. Queensland
c. Northern Territory
d. Western Australia

Unlike the quick comprehension check used by Lecturers 2 and 3 with their multiple-choice question, this multiple-choice question was used as a discussion starter.

Strongly suspecting that most of the students would say the Northern Territory, surely enough there was I think about $75,80 \%$ of the students in the tutorial did say the Northern Territory and then when I flashed up the correct answer is actually New South Wales, you could hear and physically gauge the sort of 'oh wow!' factor so, it was quite powerful in that sense with a fact like that, a numerical fact and then steering the question around that assumption of course, that's where most Indigenous people are in school. (Lecturer 6)

The Yes/No approach did not fit with this lecturer's pedagogical approach of using open- ended questions as starting points to student-centred explorations of complex topics in education. However, it was also suggested that responses to open-ended questions might be managed more effectively by having students discuss their answers and provide a smaller number of group responses, an idea which reverberates with Keller, Finkelstein, Perkins, Pollock, Turpen, \& Dubson, (2007) who assert that the most effective way of using clickers is to encourage students to discuss with their peers during clicker questions. Several guest lecturers felt that the need to be spontaneous, respond to students and interact at different points in a lecture, are pedagogical decisions that are often made intuitively within an overall student-centred framework. This situation is heightened when the lecture content is sensitive or controversial. Being able to adjust both the number and type of question, as well as monitor student comfort, were factors in prelecture decisions about the types of questions that would provide the flexibility they required. One guest lecturer commented: 
Sensitive topics like say Indigenous education or talking about race or whiteness, those sorts of topics where it is hard and there is that danger for students to get their answers out there in a public sort of forum and to have a name and a face put on it so, I'm aware of that and so you need to set up the questions in a different sort of way. (Lecturer 6)

This guest lecturer spoke about the use of questions as a reflective tool in his lectures, rather than for eliciting a verbal response or engaging with students in discussion. He said: "I would describe them as instances where I'm inviting or challenging the students to reflect on themselves and their own understanding and knowledge systems...that sort of thing”.

In this case, questions were 'quiet' prompts which did not need clicker responses. Engagement with course content, concepts or problematising scenarios, therefore, did not always need to be verbalised. However, there was recognition that student anonymity, afforded through the use of clicker questions, did provide an avenue to gauge student attitudes within a safe context, enabling them to explore their responses at a more personal level. Lecturer 6 commented in the post-survey:

The privacy of the clickers seems to allow for a genuine and widespread engagement with the questions presented to the learners and in this sense, the clickers open up space for pedagogical opportunities that are typically not available in this teaching and learning format.

When asked to describe this pedagogical space, Lecturer 6 responded:

I think it opens up the possibilities of different sorts of conversations being exposed or cultivated that otherwise, because of those concerns and fears around and with issues like Indigenous education and social justice, they're particularly sensitive and provocative and personal and risky...

By asking the guest presenters to plan their questions for clicker use, it became clear that they could employ questions to engage students in different ways to their usual, verbal, question and answer approach. Lecturer 6 was able to explain how he successfully incorporated

closed-questions around which he could lead a discussion.

So a concrete example is 'Where do you think the majority of the Indigenous students are attending schools?' I was able to put up, you know, 'New South Wales, Queensland, Northern Territory or Western Australia', say. Strongly suspecting that most of the students would say the Northern Territory, surely enough there was I think about 75, 80\% of the students in the tutorial [who] did say the Northern Territory and then when I flashed up the correct answer is actually New South Wales. You could hear and physically gauge the sort of 'Oh wow!' factor, so it was quite powerful in that sense with a fact like that, a numerical fact and then steering the question around that assumption of course, that's where most Indigenous people are in school.

This 'teachable moment', that allowed students to be "architects of their own learning and knowledge-making” (Barraket, 2005, p. 65) by providing information in a way that encourages students to question previously held beliefs and attitudes, highlights important considerations for aligning pedagogy and use of clickers. Keeping in mind the need for lecturers to feel confident in their use of new technology, and that technological problems can be solved quickly, they also need opportunities to trial the usefulness of clickers for such pedagogical moments and use different question types before presenting to a large cohort of students, in order to explore the potential of how clickers can support student-centred pedagogy. In this case study, with only a single opportunity to trial clicker use, guest lecturers generally chose the safest question type, closed questions, which generally did not align with their pedagogical approach when constructing questions. Despite the preference for open- ended questions and discussion in their lectures, one guest lecturer nevertheless commented on the benefit of having spent time clarifying the purpose of his questions and pre-empting possible student responses: "It made me think about what I was presenting, how I was going to present it, what sort of reactions I was anticipating and then where that would lead me...” (Lecturer 4).

Comparing the responses of the two guest lecturers who taught across several disciplines with those of the education lecturers, clickers were used mostly for giving students feedback and for providing opportunities to quickly gauge students' needs. For education lecturers, pedagogical decisions were based on engaging students in meaningful discussion, developing a safe space that promoted reflection on sensitive or controversial ideas, and problematising complex situations. Most lecturers chose to use multiplechoice question types or continued to include their favoured open-ended question-type. However, as this was the first time for most of the guest lecturers (all the education guest lecturers), all participants who were interviewed felt that more confidence in using alternative question-types could be gained with continued practice.

Having discussed the pedagogical beliefs and practices which inform the decisions around clicker use, we now conclude with a discussion of the implication for lecturers in the social sciences and we also propose some guidelines to contribute to future teaching design and pedagogy when using clickers.

\section{Conclusion}

Tertiary pedagogy reform has embraced online and digital tools like interactive clickers in the quest to provide learning opportunities for the growing numbers of tertiary students, many of whom are new to the university environment. The social sciences, including education, have long been interested in including students in their learning journey through student-centred pedagogies. Clickers, as a relatively new tool in the teaching repertoires of this area of higher education, offer a pathway to arrive at student-centred learning through questions that stimulate students to explore new ideas and concepts and reflect on their previous knowledge, beliefs and attitudes. The large lecture class investigated here proved to be a restriction for the open-ended questions, typically used in the humanities to encourage new ways of framing problems, for example the possible explanations for low schooling achievement in some societal groups. Most lecturers opted for closed or multiple choice questions, as time to discuss a large number of answers to open-ended questions had not been planned as a pedagogical strategy by them. However, there are many possibilities in exploring a clicker pedagogy approach in the humanities that uses clicker questions and answers mainly as a starting stimulus, to be followed by activities that create learning communities, such as peer- to-peer discussions, group activities, and competence development through participation. 
Building on previous research (Barnett, 2006; Beatty \& Gerace, 2009; Hall et al., 2005) where the academic teaching the course uses the clickers, rather than the guest lecturers in a one-off lecture, when used beyond a test-type Yes/No scenario, the results from this study suggest that clickers can effectively support lecturers' pedagogical approaches to student- centred learning. Based on our experience and the evidence collected, we therefore propose the following guidelines to contribute to future teaching design and pedagogy using clickers in humanities subjects:

- Clicker questions can function as stimulus for peer group activities to discuss complex concepts

- Open-ended questions need to be followed by time for students to discuss their answers with peers

- Closed-questions can be used to give students agency about the lecture direction, and as stimulus to expose widely held beliefs as incorrect.

This study found that education lecturers used and evaluated the benefits of clickers according to their existing pedagogical frameworks which were based mostly on constructivist learning theories, and how well they believed their objectives could be met through the different question types available to them. Whilst recognising the diverse ways in which clickers are being implemented, the researchers are also cognisant that pedagogical frameworks, and the practice of teaching, are 'situated', that is, they are performed within contextual restraints and practical (im-)possibilities. Technical issues, the interruption of 'teaching flows' and the physical setup of large courses in tiered lecture halls all contribute to what actually happens 'on the ground' when implementing a new teaching tool such as clickers.

However, teaching in tertiary settings is increasingly understood as a design science, with structured pedagogical patterns embedded in digital technologies (Laurillard, 2012).

Overcoming restraints and practical demands and impossibilities is part of an ongoing development of this science of teaching, through evidence-based improvements to our teaching strategies within an online and digitally structured teaching environment. This study shows that it is also necessary to look beyond those impediments and recognise how pedagogical approaches affect the ways in which educators adapt new technologies to their teaching and determine their educational value at the interface between teaching and learning.

\section{References}

Abrandt-Dahlgren, M., \& Öberg, G. (2001). Questioning to learn and learning to question: Structure and function of problem-based learning scenarios in environmental science education. Higher Education, 41 , 263-282.

Anderson, L.S., Healy, A. F., Kole, J. A., \& Bourne, L. E. Jr. (2011). Conserving time in the classroom: The clicker technique. The Quarterly Journal of Experimental Psychology, 6(8), 1457-1462.

Atkinson, M., \& Hunt, A. (2008). Inquiry-Guided Learning in Sociology. Teaching Sociology, 36(1), 1-7.

Barnett, J. (2006). Implementation of personal response units in very large lecture classes: Student perceptions. Australasian Journal of Educational Technology, 22(4), 474- 494.

Barraket, J. (2005). Teaching Research Method Using a Student-Centred Approach? Critical Reflections on Practice. Journal of University Teaching \& Learning Practice, 2(2), 64-74.

Beatty, I., \& Gerace, W. (2009). Technology-Enhanced Formative Assessment: A Research- Based Pedagogy for Teaching Science with Classroom Response Technology. Journal of Science Education and Technology, 18(2), 146-162.

Broussard, B. (2012). To click or not to click: Learning to teach to the microwave generation. Nurse Education in Practice, 12, 3-5.

Bullough Jr., R. V. (2012). Against best practice: Uncertainty, outliers and local studies in educational research, Journal of Education for Teaching: International research and pedagogy, 38(3), 343-357.

Caldwell, J. E. (2007). Clickers in the large classroom: Current research and best-practice tips. CBE Life Sciences Education, 6(1), 920.

Campbell, C., \& Monk, S. (2012). How do we get students talking in first year courses? Engaging students using learner response systems. Paper presented at the Society for Information Technology \& Teacher Education International Conference 2012.

Retrieved from http://www.editlib.org/

Charman, D.J. \& Fullerton, H. (1995). Interactive lectures: a case study in a geographical concepts course. Journal of Geography in Higher Education, 19, 57-68.

Ertmer, P., Sadaf, A., Ertmer, D. (2011). Student-content interactions in online courses: The role of question prompts in facilitating higher-level engagement with course content. Journal of Computing in Higher Education. 23(2-3), 157-186.

Farmer, L. (2007). What Is the Question? IFLA Journal 33(41), 41-49.

Fobes, C., \& Kaufman, P. (2008). Critical pedagogy in the sociology classroom: Challenges and concerns. Teaching Sociology, 36(1). 26-33. 
Gray, K., \& Steer, D. (2012). Personal response systems and learning: It is the pedagogy that matters, not the technology. Journal of College Science Teaching, 41(5). 80-88.

Hall, R. H., Collier, H. L., Thomas, M. L., \& Hilgers, M. G. (2005). A student response system for increasing engagement, motivation, and learning in high enrollment lectures. Paper presented at the AMCIS 2005. Paper 255. Retrieved from http://aisel.aisnet.org/amcis2005/255

Hoekstra, A., \& Mollborn, S. (2011). How clicker use facilitates existing pedagogical practices in higher education: data from interdisciplinary research on student response systems. Learning, Media and Technology(Journal Article), 1-18.

Keller, C., Finkelstein, N., Perkins, K., Pollock, S., Turpen, C., \& Dubson, M. (2007).

Research-based practices for effective clicker use. Paper presented at the Proceedings of the Physics Education Research Conference. Published by the American Institute of Physics. doi: 10.1063/1.2820913

Kerr, A. (2011). Teaching and Learning in Large Classes at Ontario Universities: An Exploratory Study. Toronto: Higher Education Quality Council of Ontario.

Koenig, K. (2010). Building acceptance for pedagogical reform through wide-scale implementation of clickers. Journal of College Science Teaching, 39(3), 46-50.

Kolikant, Y. B.-D., Drane, D., \& Calkins, S. (2010). “Clickers” as catalysts for transformation of teachers. College Teaching, 58(4), $127-135$.

Laurillard, D. (2012). Teaching as a design science. London: Routledge.

Laurillard, D. (2002). Rethinking teaching for the knowledge society. Educause Review, January/February, 16-25.

Lingard, B., Hayes, D., \& Mills,M. (2003). Teachers and productive pedagogies: contextualising, conceptualising, utilising. Pedagogy, Culture \& Society, 11(3), 399- 424.

Lyons, H. (2009). Case study research methodology for publishing developments in ICT- facilitated learning in higher education - a prescriptive approach. Innovations in Education and Teaching International, 46(1), 27-39.

McLoughlin, C. \& Lee, M. (2008). Mapping the digital terrain: New media and socialsoftware as catalysts for pedagogical change. Proceedings ascilite Melbourne. Retrieved from http://cms.ascilite.org.au/conferences/melbourne08/procs/mcloughlin.pdf

Milner-Bolotin, M., Antimirova, T., \& Petrov, A. (2010). Clickers beyond the first-year science classroom. Journal of College Science Teaching, 40(2), 14-18.

Murray, G., \& Poyatos-Matas, C. (2004). Layered teaching with large classes. Paper presented at the ETL Conference, 2004, Logan Campus, Griffith University: Retrieved from http://www98.griffith.edu.au/dspace/bitstream/handle/10072/2460/30488.pdf?sequenc e=1

Oliver, R. G. (2007). Using mobile technologies to support learning in large on campus university classes. Proceedings of ASCILITE Conference. (pp. 788-798). Singapore. Retrieved from http://www.ascilite.org.au/conferences/singapore07/procs/oliver.pdf

Patterson, B., Kilpatrick, J., \& Woebkenberg, E. (2010). Evidence for teaching practice: The impact of clickers in a large classroom environment. Nurse Education Today 30, 603-607.

Pedrosa-de-Jesus, H., da Silva Lopes, B., Moreira, A., \& Watts, M. (2012). Contexts for questioning: Two zones of teaching and learning in undergraduate science. Higher Education. 64: 557-571. DOI 10.1007/s10734-012-9512-9.

Ramsden, P. (2003). Learn to Teach in Higher Education, $2^{\text {nd }}$ Edition. London: RoutledgeFalmer.

Sevian, H. \& Robinson, W. E. (2011). Clickers Promote Learning in All Kinds of Classes - Small and Large, Graduate and Undergraduate, Lecture and Lab. Journal of College Science Teaching, 40(3), 14-18.

White, P. J. T., Delaney, D. G., Syncox, D., Akerberg, O. A., \& Alters, B. (2011). Clicker Implementation Models. EDUCAUSE Quarterly, 34(4). Retrieved from http://www.educause.edu/ero/article/clicker-implementation-models

Wit, E. (2003). Who wants to be... The Use of a PersonalResponse System in Statistics Teaching MSOR Connections, 3(2), 14-20. 